\title{
Infrared Thermometer: an accurate tool for temperature measurement during renal surgery
}

Giovanni Scala Marchini, Ricardo Jordão Duarte, Anuar Ibrahim Mitre, Bruno Camargo Tiseo, Valter Dell’Acqua Cassão, Fábio César Miranda Torricelli, Marco Antonio Arap, Miguel Srougi

Division of Urology, Clinics Hospital, University of Sao Paulo Medical School, SP, Brazil

\section{ABSTRACT}

Purpose: To evaluate infrared thermometer (IRT) accuracy compared to standard digital thermometer in measuring kidney temperature during arterial clamping with and without renal cooling.

Materials and Methods: 20 pigs weighting 20Kg underwent selective right renal arterial clamping, 10 with (Group 1 - Cold Ischemia with ice slush) and 10 without renal cooling (Group 2 - Warm Ischemia). Arterial clamping was performed without venous clamping. Renal temperature was serially measured following clamping of the main renal artery with the IRT and a digital contact thermometer (DT): immediate after clamping (T0), after 2 (T2), 5 (T5) and 10 minutes (T10). Temperature values were expressed in mean, standard deviation and range for each thermometer. We used the $\mathrm{T}$ student test to compare means and considered $\mathrm{p}<0.05$ to be statistically significant.

Results: In Group 1, mean DT surface temperature decrease was $12.6 \pm 4.1^{\circ} \mathrm{C}\left(5-19^{\circ} \mathrm{C}\right)$ while deep DT temperature decrease was $15.8 \pm 1.5^{\circ} \mathrm{C}\left(15-18^{\circ} \mathrm{C}\right)$. For the IRT, mean temperature decrease was $9.1 \pm 3.8^{\circ} \mathrm{C}\left(3-14^{\circ} \mathrm{C}\right)$. There was no statistically significant difference between thermometers. In Group 2, surface temperature decrease for DT was $2.7 \pm 1.8^{\circ} \mathrm{C}$ $\left(0-4^{\circ} \mathrm{C}\right)$ and mean deep temperature decrease was $0.5 \pm 1.0^{\circ} \mathrm{C}\left(0-3^{\circ} \mathrm{C}\right)$. For IRT, mean temperature decrease was $3.1 \pm 1.9^{\circ} \mathrm{C}\left(0-6^{\circ} \mathrm{C}\right)$. No statistically significant difference between thermometers was found at any time point.

Conclusions: IRT proved to be an accurate non-invasive precise device for renal temperature monitoring during kidney surgery. External ice slush cooling confirmed to be fast and effective at cooling the pig model.

\section{ARTICLE INFO}

\section{Key words:}

Renal Blood Flow, Effective; Ischemia; Infrared Rays;

Thermometers

Int Braz J Urol. 2013; 39: 572-8

Submitted for publication: January 22, 2013

Accepted after revision: July 02, 2013

\section{INTRODUCTION}

Ideal kidney temperature during arterial clamping procedures was determined four decades ago by Wickham et al. (1) and confirmed by Ward (2) to be around $15^{\circ} \mathrm{C}$. However, intraoperative assessment of kidney temperature during cooling and/or ischemia procedures are not routinely performed and poorly studied. Even when different renal cooling techniques are compared, whether in animals or humans, there is no standardization for such measurement (3-10).

Infrared thermometers (IRT) are widely used for industrial purposes and have been recently incorporated in clinical practice worldwide. IRT infer temperature by using a portion of the thermal radiation emitted by the object of measurement. Its accuracy has been tested in several centers for evaluation of febrile patients and some authors found reliable results when compared to 
standard mercury thermometer $(11,12)$. Others could not obtain the same results and controversy persists $(13,14)$. Nonetheless, IRT showed great accuracy when measuring temperature of fluids to be administered intravenously (15) and it has been proved reliable when monitoring plastic surgery grafts (16). To date, there are no clinical or experimental researches testing IRT for temperature monitoring during renal ischemia and/or cooling procedures. The purpose of our research was to evaluate IRT accuracy and precision in measuring renal temperature compared to standard digital contact thermometer.

\section{MATERIALS AND METHODS}

\section{Swine Experimental Model}

The Ethics Committee for Animal Experimentation of our Institution approved the experimental protocol. Between December/2010 and February/2011, 20 domestic male pigs weighing $20 \mathrm{Kg}$ were used in the experiment. All procedures were performed under general anesthesia: after preoperative fasting of at least 8 hours, they were submitted to sedation with ketamine $(12 \mathrm{mg} / \mathrm{kg})$ and xylazine ( $2 \mathrm{mg} / \mathrm{kg}$ ), inhalatory anesthesia with isoflurane, and were intubated for mechanical ventilation. Cardiac rate, pulse oximetry and blood pressure were constantly monitored. Operating room temperature was maintained between 20 and $25^{\circ} \mathrm{C}$. All animals underwent right subcostal incision of $10 \mathrm{~cm}$, followed by renal capsule release, renal hilum exposure and selective identification of renal vessels. Only one renal unit was manipulated per pig. Each kidney was subsequently submitted to experimental conditions described bellow.

\section{Temperature Measurement}

Pig temperature was obtained using standard rectal thermometer. Renal arterial clamping was performed without venous clamping. Renal temperature was serially measured following clamping of the main renal artery: temperature values were obtained immediate after clamping (T0), after 2 (T2), 5 (T5) and 10 minutes (T10). The procedure was performed in 10 pigs with renal cooling (Group 1 - Cold Ischemia) and in 10 animals without renal cooling (Group 2 - Warm Ischemia). A computer program was used for animal randomization. Cooling was obtained by placing $4^{\circ} \mathrm{C}$ ice slush in $90 \%$ of total renal surface. The ice-free surface was used for temperature measurement. By using the digital contact thermometer (DT), we assured similar temperature was obtained both in ice covered and ice-free areas. In both groups, renal temperature was simultaneously measured with a DT and IRT (Figure-1). DT was used to measure not only surface but also deep kidney temperatures during the experiment in order to assure homogeneous kidney cooling. As a result, two temperature curves for DT and a third curve for the IRT were obtained in Groups 1 and 2.

\section{Thermometer Characteristics and Specifications}

IRT: a portable infrared thermometer (Minipa ${ }^{\circledR}$, model MT-360) with laser pointer and LCD display was used for non-contact temperature measurement. Specifications according to manufacturer were: temperature precision of $2^{\circ} \mathrm{C}$ within a temperature variation of -30 to $100^{\circ} \mathrm{C}$, distance-to-spot ratio of 10:1, emissivity of 0.1 to 1.0 and response time of $250 \mathrm{~ms}$. Emissivity was adjusted to 0.98 . To include a renal surface diameter of at least $5 \mathrm{~mm}$ we performed temperature measurement with the device in a $5 \mathrm{~cm}$ range from the kidney in a 90-degree angle, according to manufacturer instructions.

Figure 1 - Schematic Swine Model for simultaneous kidney temperature measurement with IRT and DT during renal ischemia procedures.

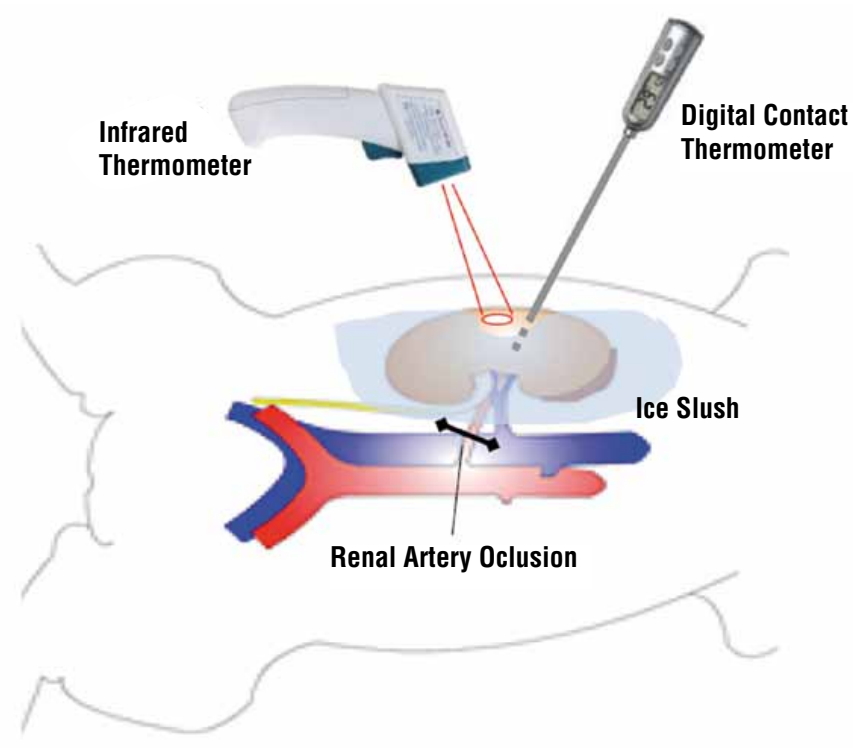


DT: we used a waterproof digital contact thermometer (Incoterm ${ }^{\circledR}$, model 9791.16.0.00) with a $1{ }^{\circ} \mathrm{C}$ measurement precision and temperature window scale of -50 to $300^{\circ} \mathrm{C}$. The device rigid metal tip was inserted in the renal parenchyma with maximum depth of $10 \mathrm{~mm}$ (surface DT temperature). Also, it was inserted deeply in renal parenchyma with a depth of $30 \mathrm{~mm}$ in a 45-degree angle to ensure parenchyma temperature measurement (deep DT temperature). Temperature was measured until the sound alarm was heard according to manufacturer instructions.

\section{Comparative and Statistic Analyses}

Temperature values at each time point were expressed in mean, standard deviation and range for each thermometer in all groups. Temperature curves of IRT and DT were compared in Groups 1 and 2. We used the Kolmogorov-Smirnov test to assure data normality. The Student-T test was used to compare mean values at each time point (T0, T2, T5, T10) between the different thermometers. We considered $\mathrm{p}<0.05$ to be statistically significant.

\section{RESULTS}

\section{Group 1 - Cold Ischemia $(\mathrm{n}=10)$}

Mean swine temperature was $34.2 \pm 1.7^{\circ} \mathrm{C}$ $\left(31-37^{\circ} \mathrm{C}\right)$. Figure-2A shows temperature curves in renal cold ischemia group for the two thermometers. For the DT, mean surface temperature decrease was $12.6 \pm 4.1^{\circ} \mathrm{C}\left(5-19^{\circ} \mathrm{C}\right.$; Table-1). At T5 and T10, 8 and 9 of 10 animals had surface renal temperature $\leq 15^{\circ} \mathrm{C}$, respectively. All had kidney temperature below $20^{\circ} \mathrm{C}$ already at T5. Mean deep temperature decrease was $15.8 \pm 1.5^{\circ} \mathrm{C}\left(15-18^{\circ} \mathrm{C}\right)$. For the IRT, mean temperature decrease was 9.1 $\pm 3.8^{\circ} \mathrm{C}\left(3-14^{\circ} \mathrm{C}\right)$. At T5 and T10, $70 \%$ and $80 \%$ of animals had kidney temperature $\leq 15^{\circ} \mathrm{C}$, respectively. All had renal temperature below $20^{\circ} \mathrm{C}$ already at $\mathrm{T} 5$. There was no statistically significant difference between thermometers.

\section{Group 2 - Warm Ischemia $(\mathrm{n}=10)$}

Mean animal temperature was $34.9 \pm$ $1.3^{\circ} \mathrm{C}\left(33-36^{\circ} \mathrm{C}\right)$. Temperature curves in renal warm ischemia group for both thermometers are exposed on Table-2. Mean surface temperature decrease for DT was $2.7 \pm 1.8^{\circ} \mathrm{C}\left(0-4^{\circ} \mathrm{C}\right.$; Figure-2B). Mean deep temperature decrease was 0.5 $\pm 1.0^{\circ} \mathrm{C}\left(0-3^{\circ} \mathrm{C}\right)$. For the IRT, mean temperature decrease was $3.1 \pm 1.9^{\circ} \mathrm{C}\left(0-6^{\circ} \mathrm{C}\right)$. No statistically significant difference between thermometers was found at any time point.

\section{DISCUSSION}

Transitory interruption of kidney blood supply is a necessary step in particular for urological procedures such as partial nephrectomy, renal transplantation and renovascular surgery. Methods to decrease cellular metabolism are required to

Figure 2 - Mean temperature decrease during cold $(A)$ and warm $(B)$ renal ischemia measured by digital and infrared thermometers.
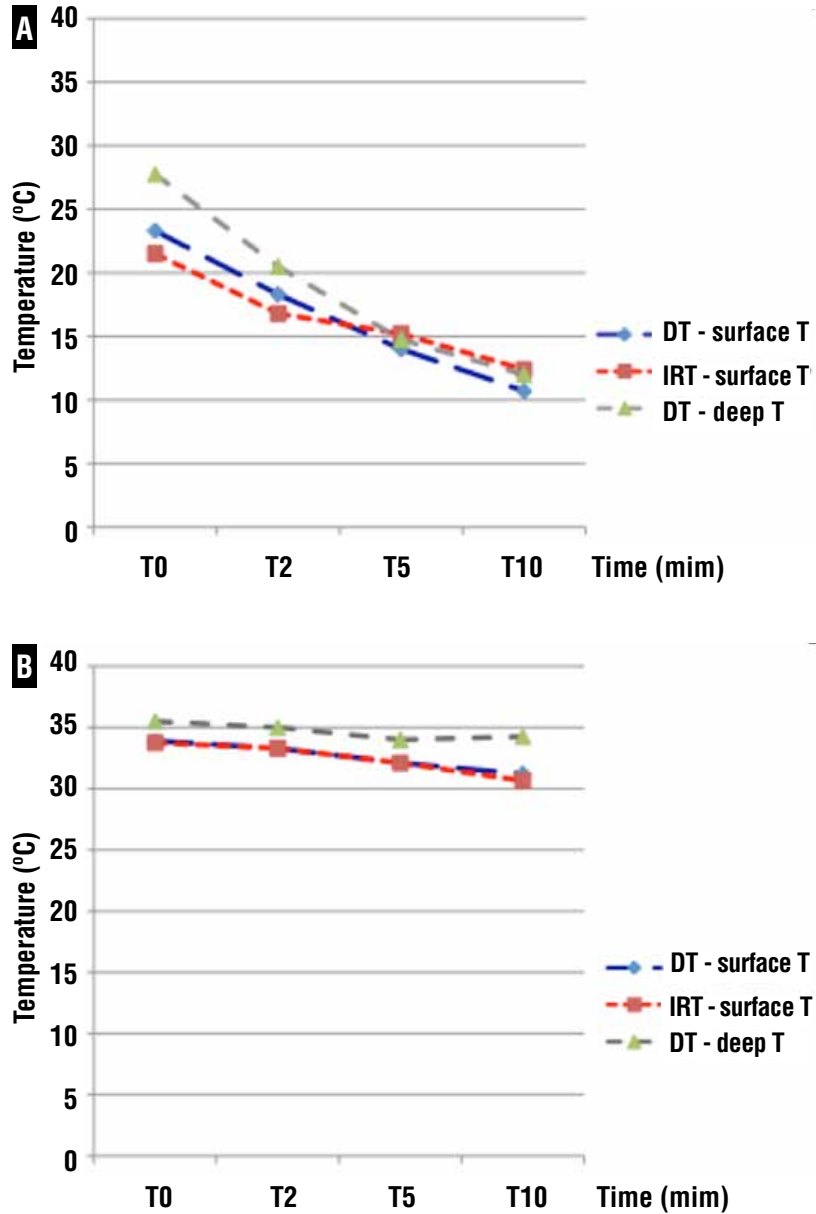
Table 1 - Comparative analysis of temperature decrease during cold renal ischemia procedure.

\begin{tabular}{lccccccc}
\hline & \multicolumn{2}{c}{ IRT } & \multicolumn{2}{c}{ DT - surface } & \multicolumn{2}{c}{ DT - deep } \\
\hline Time Point & Mean \pm SD & (range) & Mean \pm SD & (range) & Mean \pm SD & (range) & $p$ \\
\hline T0 & $21.5 \pm 5.9$ & $(8-30)$ & $23.3 \pm 4.9$ & $(12-29)$ & $27.8 \pm 3.3$ & $(24-32)$ & 0.46 \\
T2 & $16.8 \pm 5.9$ & $(8-28)$ & $18.3 \pm 5.5$ & $(8-25)$ & $20.5 \pm 5.4$ & $(16-28)$ & 0.56 \\
T5 & $15.2 \pm 3.5$ & $(12-23)$ & $14.0 \pm 3.0$ & $(8-19)$ & $14.8 \pm 2.5$ & $(12-18)$ & 0.42 \\
T10 & $12.4 \pm 3.3$ & $(7-16)$ & $10.7 \pm 2.6$ & $(7-15)$ & $12.4 \pm 3.6$ & $(9-17)$ & 0.22 \\
\hline Variation & $\mathbf{9 . 1} \pm \mathbf{3 . 8}$ & $\mathbf{( 3 - 1 4 )}$ & $\mathbf{1 2 . 6} \pm \mathbf{4 . 1}$ & $\mathbf{( 5 - 1 9 )}$ & $\mathbf{1 5 . 8} \pm \mathbf{1 . 5}$ & $\mathbf{( 1 5 - 1 8 )}$ & $\mathbf{0 . 0 6}$ \\
\hline
\end{tabular}

IRT = Infrared thermometers; $\mathbf{D T}=$ Digital contact thermometer; $\mathbf{S D}=$ Standard deviation

Table 2 - Comparative analysis of temperature decrease during warm renal ischemia procedure.

\begin{tabular}{lccccccc}
\hline & \multicolumn{2}{c}{ IRT } & \multicolumn{2}{c}{ DT - surface } & \multicolumn{2}{c}{ DT - deep } \\
\hline Time Point & Mean \pm SD & (range) & Mean \pm SD & (range) & Mean \pm SD & (range) & $p$ \\
\hline T0 & $33.8 \pm 1.0$ & $(32-35)$ & $33.9 \pm 1.3$ & $(32-36)$ & $35.5 \pm 1.3$ & $(34-37)$ & 0.77 \\
T2 & $33.3 \pm 1.3$ & $(31-36)$ & $33.3 \pm 1.3$ & $(31-36)$ & $35.0 \pm 0.8$ & $(34-36)$ & 1.0 \\
T5 & $32.1 \pm 1.4$ & $(30-34)$ & $32.1 \pm 2.0$ & $(29-36)$ & $34.0 \pm 1.2$ & $(33-35)$ & 1.0 \\
T10 & $30.7 \pm 2.0$ & $(28-34)$ & $31.2 \pm 2.5$ & $(29-37)$ & $34.3 \pm 1.0$ & $(33-35)$ & 0.65 \\
\hline Variation & $\mathbf{3 . 1} \pm \mathbf{1 . 9}$ & $\mathbf{( 0 - 6 )}$ & $\mathbf{2 . 7} \pm \mathbf{1 . 8}$ & $\mathbf{( 0 - 4 )}$ & $\mathbf{0 . 5} \pm \mathbf{1 . 0}$ & $\mathbf{( 0 - 3 )}$ & $\mathbf{0 . 6 2}$ \\
\hline
\end{tabular}

IRT = Infrared thermometers; $\mathbf{D T}=$ Digital contact thermometer; $\mathbf{S D}=$ standard deviation

prevent ischemic-reperfusion injury, being external renal cooling with ice slush the most accepted technique. The first authors to examine this matter were Wickham et al. in 1967 (1), followed by Ward who used a canine model and determined $15^{\circ} \mathrm{C}$ to be the ideal temperature to avoid renal damage caused by ischemia and reperfusion phenomenon (2). Since then, such figures have been adopted as goals every time renal cooling is required. Although effortless to execute in conventional surgeries, accurate ice slush placement during laparoscopic procedures is technically demanding and less attractive. For that reason, new renal cooling methods have been created (3-10). Each method has its pros and cons, none being able to completely reproduce the gold-standard open technique. That led many surgeons to perform laparoscopic partial nephrectomy without renal vascular clamping. The temperature of renal tissue during warm ischemia has been poorly investigated. A maximum warm ischemia time of 30 minutes is supposed to avoid permanent renal damage $(17,18)$. However, even in excellence laparoscopic centers a longer ischemia time is reported (19), in part explaining why laparoscopic partial nephrectomy is underperformed worldwide (20).

To date, we are the first to test IRT accuracy during renal surgery. IRT infer temperature by using a portion of the thermal radiation emitted by the object of measurement. If a laser is used to help aim the thermometer at certain 
distance it is called laser non-contact thermometer. The basic design consists of a lens to focus the infrared thermal radiation on to a detector, which converts radiant power to an electrical signal that can be displayed in units of temperature after being compensated for ambient temperature. Specifications of portable handheld sensors include ratings of temperature accuracy, distance-to-spot ratio (D:S) and emissivity. In general, measurement uncertainty remains around $\pm 2^{\circ} \mathrm{C} / \pm 4^{\circ} \mathrm{F}$. D : $\mathrm{S}$ ratio is the relationship between object distance and diameter of the temperature measurement area. Finally, the sensor may have an adjustable emissivity setting, which can be set to measure the temperature of shiny and non-reflective surfaces. The value of emissivity for various materials can be looked up in published emissivity table. We adjusted emissivity to 0.98 because it is the closest to renal tissue.

Initial studies testing IRT accuracy and practicability were undertaken for febrile patients evaluation. Results vary among series with some disappointing $(13,14)$ and other promising reports $(11,12)$. Our experiment showed excellent accuracy of the IRT compared to digital contact thermometer. We found no difference in temperature values in each time point studied. Also, IRT proved to be reliable not only during small temperature variation but also for sizeable variations. IRT was very comfortable to manipulate during the experiment and we faced no problems following manufacturer instructions. In addition, it is a non-contact device and facilitates temperature measurement without increasing the risk of tissue damage or contamination. This is a serious advantage when temperature measurement is required. The device may have a potential use in lap/robotic procedures and could be used together with the camera or even built-in. Although initially planned, a cost analysis was not done because thermometers' prices are very similar. Therefore, being an uncomplicated, innocuous and low-cost new technology, its incorporation in surgical routine is mainly dependent on its availability in an integrated system with laparoscopic cameras.

We could assess real effectiveness of ice slush renal cooling. The essential issue in achie- ving hypothermia is to ensure that the hypothermia is uniform throughout the kidney surface, cortex and the medulla and is constant during the procedure. Desired renal temperatures bellow were already achieved after five minutes of renal cooling in all animals of our experiment. If cutoff value was $15^{\circ} \mathrm{C}$, at T5 and T10 $70-80 \%$ and $80-90 \%$ of kidneys were adequately cooled, respectively. We confirmed data from other studies proving ice slush to be an excellent fast and efficient method for renal cooling $(10,17,18)$. Gill et al. achieved a nadir renal parenchymal temperature of 5 to $19^{\circ} \mathrm{C}$ by using ice slush during laparoscopic partial nephrectomy in humans (21). Guerra et al. recently compared ice slush with retrograde ureteral cold saline perfusion during experimental renal cooling (10). In the ice slush group, they obtained a mean renal temperature decrease rate of $1.37^{\circ} \mathrm{C}$ per minute in the medulla and $1.44^{\circ} \mathrm{C}$ per minute in renal cortex during the first 20 minutes. After 5 and 10 minutes, mean renal temperature was $17^{\circ} \mathrm{C}$ and $12^{\circ} \mathrm{C}$, respectively. Those findings are very similar to ours. Small differences may be related to animal size and weight. In humans, temperature decrease may be a little slower because of renal parenchyma thickness.

The clinical application of IRT is still to be established. Most surgical procedures concerning renal cooling are performed without routine measurement of kidney temperature. This occurs mainly because gained experienced proved it to be feasible and safe when the expected ischemia time is shorter then 20 to 30 minutes. The proposal for IRT use is not to avoid renal ischemia, but to prevent renal-ischemia reperfusion lesion due to a non-ideal ischemia temperature during renal pedicle clamping surgeries. If available within the laparoscopic or robotic camera it could be used for testing of new cooling techniques with the advantage of being a non-contact device as already discussed. Moreover, with the advances in nephron-sparing surgery and trend towards very selective clamping (22), the IRT could be used to define the area without blood flow after the desired branch of renal artery was occluded during partial nephrectomy procedures just by establishing temperature differences. 
Finally, monitoring of renal temperature during those procedures may have an even more important role when a clinical research with strict methodological standards is being carried on. For example, accurate renal cooling should be assessed every time a serum or histological analysis is being undertaken in such organs or individuals. In addition, and not less important, IRT may be appropriate for investigative laboratory studies assessing methods or effects of kidney cooling during open renal procedures.

\section{CONCLUSIONS}

IRT proved to be an accurate device for renal temperature monitoring during cold and warm ischemia procedures. The noncontact infrared thermometer is a non-invasive precise tool witch allows effortless temperature measurement during kidney surgery. External ice slush cooling confirmed to be fast and effective at cooling in the pig model.

\section{ABBREVIATIONS}

IRT $=$ Infrared thermometer

DT $=$ Digital contact thermometer

$\mathrm{D}: \mathrm{S}=$ Distance-to-spot ratio

\section{CONFLICT OF INTEREST}

None declared.

\section{REFERENCES}

1. Wickham JE, Hanley HG, Joekes AM: Regional renal hypothermia. Br J Urol. 1967; 39: 727-43.

2. Ward JP: Determination of the Optimum temperature for regional renal hypothermia during temporary renal ischaemia. Br J Urol. 1975; 47: 17-24.

3. Beri A, Lattouf JB, Deambros 0, Grüll M, Gschwendtner M, Ziegerhofer J, et al.: Partial nephrectomy using renal artery perfusion for cold ischemia: functional and oncologic outcomes. J Endourol. 2008; 22: 1285-90.

4. Janetschek G, Abdelmaksoud A, Bagheri F, Al-Zahrani H, Leeb K, Gschwendtner M: Laparoscopic partial nephrectomy in cold ischemia: renal artery perfusion. J Urol. 2004; 171: 68-71.
5. Landman J, Rehman J, Sundaram CP, Bhayani S, Monga M, Pattaras JG: Renal hypothermia achieved by retrograde intracavitary saline perfusion. J Endourol. 2002; 16: 445-9.

6. Crain DS, Spencer CR, Favata MA, Amling CL: Transureteral saline perfusion to obtain renal hypothermia: potential application in laparoscopic partial nephrectomy. JSLS. 2004; 8: 217-22.

7. Rama Raju BV, Atm Prakash, Kapur M, Gulati SM: Acute renal ischaemia and the effect of local hypothermia on the histological changes: an experimental study. Indian J Med Res. 1969; 57: 925-31.

8. Webster TM, Moeckel GW, Herrell SD: Second prize: simple method for achieving renal parenchymal hypothermia for pure laparoscopic partial nephrectomy. J Endourol. 2005; 19: 1075-81.

9. Kijvikai K, Viprakasit DP, Milhoua P, Clark PE, Herrell SD: A simple, effective method to create laparoscopic renal protective hypothermia with cold saline surface irrigation: clinicalapplication and assessment. J Urol. 2010; 184: 1861-6.

10. Guerra R, Leonardi EP, Otsuka RA, Quitzan J, Kawano PR, Yamamoto HA, et al.: Cold renal ischemia: comparison of efficacy between two techniques of cooling, in a swine model. J Endourol. 2010; 24: 445-9.

11. Nguyen AV, Cohen NJ, Lipman H, Brown CM, Molinari NA, Jackson WL, et al.: Comparison of 3 infrared thermal detection systems and self-report for mass fever screening. Emerg Infect Dis. 2010; 16: 1710-7.

12. Osio CE, Carnelli V: Comparative study of body temperature measured with a non-contact infrared thermometer versus conventional devices. The first Italian study on 90 pediatric patients. Minerva Pediatr. 2007; 59: 327-36.

13. Fortuna EL, Carney MM, Macy M, Stanley RM, Younger JG, Bradin SA: Accuracy of non-contact infrared thermometry versus rectal thermometry in young children evaluated in the emergencydepartment for fever. J Emerg Nurs. 2010; 36: 101-4

14. Hausfater P, Zhao Y, Defrenne S, Bonnet P, Riou B: Cutaneous infrared thermometry for detecting febrile patients. Emerg Infect Dis. 2008; 14: 1255-8.

15. Lapostolle F, Catineau J, Le Toumelin P, Proust C, Garrigue $B$, Galinski $\mathrm{M}$, et al.: Intravenous fluid temperature management by infrared thermometer. Am J Emerg Med. 2006; 24: 174-6.

16. Estrella EP: An infrared forehead thermometer for flap monitoring. J Plast Reconstr Aesthet Surg. 2009; 62: 736.

17. Ramani AP, Ryndin I, Lynch AC, Veetil RT: Current concepts in achieving renal hypothermia during laparoscopic partial nephrectomy. BJU Int. 2006; 97: 342-4.

18. Lane BR, Babineau DC, Poggio ED, Weight CJ, Larson BT, Gill IS, et al.: Factors predicting renal functional outcome after partial nephrectomy. J Urol. 2008; 180: 2363-8; discussion 2368-9. 
19. Gill IS, Kavoussi LR, Lane BR, Blute ML, Babineau D, Colombo JR Jr, et al.: Comparison of 1,800 laparoscopic and open partial nephrectomies for single renal tumors. J Urol. 2007; 178: 41-6.

20. Gerber GS, Stockton BR: Laparoscopic nephron-sparing surgery. J Endourol. 2007; 21: 458-9.
21. Gill IS, Abreu SC, Desai MM, Steinberg AP, Ramani AP, Ng C, et al.: Laparoscopic ice slush renal hypothermia for partial nephrectomy: the initial experience. J Urol. 2003; 170: 52-6.

22. Gill IS, Patil MB, Abreu AL, $\mathrm{Ng} \mathrm{C}$, Cai J, Berger A, et al.: Zero ischemia anatomical partial nephrectomy: a novel approach. J Urol. 2012; 187: 807-14.

Correspondence address: Dr. Giovanni Scala Marchini Division of Urology, Clinics Hospital, University of Sao Paulo Medical School Av. Dr. Enéas Carvalho de Aguiar, 255

Sao Paulo, SP. 05403-000, Brazil Telephone: +55 11 2661-8080

E-mail: gsmarchini@hotmail.com 